\title{
PREPARO DA GESTANTE PARA O PARTO. AULAS TEÓRICO-PRÁTICAS.
}

\author{
Maria José Schmidt * \\ Wanda Escobar da Silva Freddi **
}

\begin{tabular}{l|l|}
\cline { 2 - 2 } & $\mathrm{RBEn} / 02$ \\
\hline
\end{tabular}

SCHMIDT, M.J. \& FREDDI, W.E.S. - Preparo da gestante para o parto. Aulas teórico-práticas, Rev. Bras. Enf.; Rio de Janeiro, $28: 15-25,1975$.

\section{INTRODUÇÃO}

Nas séries anteriores, demos ênfase aos dois métodos básicos de preparo da gestante para o parto (método de Read e método Psicoprofilático), e apresentamos algumas sugestões para a formação de uma equipe especializada para o ensino teórico-prático dos mesmos. Ressaltamos que o preparo da gestante para o parto, exige uma equipe harmoniosa na qual cada membro desempenha um papel importante. Além disso, explicamos que, para haver pleno êxito do método exposto, é importante, também, uma maternidade que ofereça em ambiente adequado para a gestante dar a luz; a assistência deve ser feita por pessoal que, além da competência técnica, tenha, também serenidade e calma no desempenho de suas funções. Neste artigo, o último desta série, descrevemos um curso de preparo psicofísico para o parto, baseado principalmente nos métodos de Read e Psico- profilático. Este curso vem sendo dado, há alguns anos, por Maria José Schmidt: com indiscutivel êxito.

Os resultados da aplicação dos exercícios, durante o trabalho de parto, foram apresentados, em relatórios, por mães, seus familiares e pelos profissionais que as assistiram; tais resultados foram por nós classificados em ótimn bom, regular e mau. Das 366 gestantes preparadas, $82,25 \%$ (301) foram avaliadas como "ótimas", pois, durante o trabalho de parto, usaram os exercícios aprendidos e ficaram entusiasmadas com a experiência do parto; $10,38 \%$ (38) foram considerados "boas", pois embora fazendo os exercícios e tendo gostado da experiência do parto, nẳo apresentaram grande entusiasmo por esta. Como resultado regular foram classificadas $6,83 \%$ (25), que usaram apenas alguns exercícios e se descon-

* Enfermeira Obstétrica da Superintendéncia do INPS em São Paulo

** Professora da Escola de Enfermagem da USP. 
SCHMIDT, M.J. \& FREDDI, W.E.S. - Preparo da gestante para o parto. Aulas teórico-práticas, Rev. Bras. Enf.; Rio de Janeiro, 28 : 15-25, 1975.

trolaram. Apenas 0,54\% (2) não fizeram os exercícios e se descontrolaram tanto no trabalho de parto como no parto. Isto nos animou a continuar a aplicação e a divulgação deste curso de preparo psicofísico para o parto.
O nosso propósito, portanto, é de apresentar os assuntos e as ginásticas utilizadas neste curso, de um modo prático, para que os profissionais interessados em preparar gestantes para 0 parto possam aplicá-lo com facilidade

\section{CURSO DE PREPARAÇÃO PSICO-FÍSICA PARA O PARTO}

O objetivo principal desse curso é preparar a gestante para que ela participe ativamente de $\approx u$ parto, sentindo-se segura, confortável e esclarecida quanto ao que acontece com ela e com o seu filho, durante a gravidez, o parto e o puerpéro, e para o que poderá fazer em cada situação.

Os grupos de gestantes devem ser formados em um máximo de 10 alunas e num mínimo de 4, possibilitando-se o diálogo e favorecendo a narrativa de preocupações, temores, tabus e facilitando, ainda, o descondicionamento de fatores negativos que interferem no parto, substituindo-os por fatores positivos.

Os grupos deverão ser de preferência, o mais homogêneos possível, tanto no aspecto de instrução, sócio-econômico, como também no de paridade e época de gestação. As ginásticas poderão iniciar-se a partir do $50^{\circ}$ mês de gravidez. A seleção das gestantes para os diversos grupos poderá ser feita usando-se a ficha de pré-natal ou uma ficha especial, com anamnese individual detalhada, tanto somática como psicológica.

A sala de aula poderá ser dividida em dois ambientes, um para as aulas teóricas e outro para as aulas práticas, ou, terminando-se a aula teórica, transformar-se a sala em ambiente para ginástica. A mesma deverá obedecer aos requisitos técnicos de construção, isto é: ser ampla, arejada e com pintura em cor clara, proporcionando o clima psicológico adequado ao relaxamento muscular. O piso não deve ser de material frio, o que dificultaria, ou mesmo impediria esse relaxamento. A existência de sanitários próximos à sala de aula ofe. recerá maior conforto às gestantes.

A sala de aula teórica deverá conter: cadeiras confortáveis, colocadas em semi-círculo; mesa secretária e cadeira para o professor; lousa e acessórios (giz e apagador); suporte para álbum seriado ou outro tipo de material áudiovisual, como por exemplo: cartazes ou folhetos; resumos mimiografados das aulas teóricas e práticas, com figuras demonstrativas das ginásticas, e, quando possivel, manequim e boneco para demonstração do parto e cuidados do bebê; projetor de "slides" ou retroprojetor.

A sala ou ambiente para as aulas de ginástica deverá conter: cadeiras confortáveis, colchonetes de espuma de nylon (ou cobertor, esteira ou toalha de banho, ou papel grosso para forrar o chão), travesseiro para apoío da cabeça, quando a gestante achar necessário. $\mathrm{O}$ vestuário para ginástica deverá ser folgado e adequado, para não impedir os movimentos e não constranger as gestantes, podendo ser usado calça comprida, pijama curto ou comprido, ou ainda, bermuda.

O curso é ministrado em oito aulas, sendo uma aula por semana, com du- 
SCHMIDT, M.J. \& FREDDI, W.E.S. - Preparo da gestante para o parto. Aulas teórico-práticas, Rev. Bras. Enf.; Rio de Janeiro, 28 : 15-25, 1975.

ração de duas horas, aproximadamente. O ideal seria acrescentar mais duas aulas especiais para os maridos. O horário a ser escolhido deverá atender à facilidade da maioria das gestantes e as aulas especiais em dia e hora que também possibilite a frequência dos pais.

\section{MÉTODO DIDÁTICO}

As aulas teóricas devem ser expositivas, com a participação das gestantes e duração de, aproximadamente, trinta minutos. Sempre que possivel, deverá ser usada a discussão em grupo, com questōes simples, apresentadas pelas próprias gestantes ou pelo professor.

As aulas práticas constarão de:

- demonstração, devolução e treinamento das técnicas de respiração profunda, de respiração ofegante, de respiração do periodo expulsivo, do relaxamento muscular e das ginásticas;

- demonsração das ginásticas de pós-parto;

- demonstração da técnica de parto (se possivel, usando o manequim), do banho do bebê e do preparo da mamadeira.

As gestantes deverão treinar os exercícios diariamente, em casa, escolhendc um horário apropriado, iniciando com a repetição de duas vezes cada exercício e aumentando gradativamente cada três dias mais uma repetição, até atingir cinco vezes cada exercício. No fim do curso, a gestante deverá estar fazendo cinco vezes cada exercício, num total de quarenta e cinco.

\section{Primeira Aula}

Apresentamos esta aula com mais detalhes e com sugestões, pois isto é fundamental para o descondicionamento da gestante.

Parte teórica - introdução ao curso.

Objetivo: motivar as gestantes para uma preparação física e psicológica para o momento do parto, tendo em vista, principalmente, que os exercícios serão feitos em casa.

Desenvolvimento do assunto:

A - Orientação quanto ao local, horário, número de aulas e conteúdo do programa.

B - Fatores que interferem no parto:

CONTRAÇAO = SUGESTAO + IGNORANCIA + SOLIDAOO + MEDO + TENSAO $=$ DOR = DISTÓCIA FUNCIONAL = ESGOTAMENTO DO SISTEMA NERVOSO.*

Contração - explicar que o parto é um fenômeno natural e que a contração uterina é o trabalho do útero para fazer nascer o bebê. Que essa contração é erroneamente chamada de "dor" do parto (perguntar às gestantes o que é "dor" e analisar com elas a dor física, psíquica e moral e fazer a comparação da contração uterina com o trabalho do estômago, do intestino e da bexiga, que também expelem o seu conteúdo, de modo semelhante, sem dor).

Sugestão - analisar os condicionamentos positivos e negativos da infância, adolescência, o ambiente social e familiar que no momento do parto sugestionam a parturiente. Explicar que a mulher, desde criança, ouve falar do parto como evento terrificante, e que são os próprios familiares e amigos que inconsciente e insistentemente, incumbem-se de dramatizar a situação. Que também os meios de comunicação,

CERRUOT, F. - Nossa experiência no assim chamado parto sem dor. Revista Ginecológica e D'Obstetrlcia 99: 745-766, outubro 1956. 
SCHMIDT, M.J. \& FREDDI, W.E.S. - Preparo da gestante para o parto. Aulas teórico-práticas, Rev. Bras. Enf.; Rio de Janeiro, 28 : 15-25, 1975.

como o cinema, o rádio e a televisão, atribuem sofrimentos fantásticos ao parto, favorecendo um condicionamento negativo, que pode determinar na parturiente, uma atitude de fuga no momento da participação, ou seja, ela enfrenta o trabalho de parto contra a sua vontade e se revolta porque poderia estar "livre" daquele momento se tivesse seguido os conselhos recebidos. Analisar a corrente negativa que leva a parturiente ao sofrimento do parto, indicando a solução para interrompêla e formar outra positiva, que conduz à satisfação de dar a luz. Evidenciar as alegrias da maternidade, preparando as futuras mães para a educação dos filhos que estão por nascer. Procurar, conscientemente, substituir os condicionamentos negativos por sugestões positivas, explicando o porquê de cada acontecimento, preparando-a para a "festa de formatura" onde, na maternidade receberá o seu "diploma", tão esperado durante os nove meses de gestação, vivo e chorando.

Ignorância - explicar que o desconhecimento de como se processa a gravidez e o parto, e, principalmente, do que vai acontecer naquele parto, deixa a mãe insegura e descontrolada. Contudo, quando a mulher conhece os fenômenos normais da gravidez e do parto, principalmente a fisiologia das contrações e a técnica de dar a luz, sentir-se-á segura e confortável.

Solidão - mostrar que é natural a parturiente sentir-se só e abandonada no momento do parto, pois não pode transferir para outrem a responsabilidade de fazer nascer seu filho. Mas que, quando assume com amor esta tarefa importante, e conhece o médico e o hospital que escolheu, procederá tranquilamente, mesmo que os comentários do pessoal hospitalar sejam negativos, sentindo-se segura e partici- pante de uma equipipe (mãe, filho e profissionais).

Medo - explicar que o medo é consequência da insegurança (medo do desconhecido), da ignorância e da solidão; logo, quando a parturiente acompanha o seu trabalho de parto usando as técnicas ensinadas no curso, sentirse-á confiante e não terá medo.

Tensão muscular - evidenciar que o medo desencadeia a tensão muscular que, por sua vez, contrai o colo do útero, influindo na sua dilatação; as contrações empurram o bebê contra 0 colo, que oferece resistência, e isto causa dores. Para evitar a tensão muscular e recuperar as energias gastas durante a contração, a parturiente deverá fazer o relaxamento muscular que aprendeu no curso e treinou durante a gravidez.

Dor - ensinar que, normalmente, a tensão provoca dores físicas e psicológicas, e que a dor, aumentada pelo medo, aumenta a tensão, produzindo mais dor. Assim, fica estabelecido um círculo vicioso, levando a parturiente a um descontrole emocional e à distócia funcional que, por sua vez, conduz a um esgotamento do sistema nervoso. Contudo, quando a mulher está preparada física e psiquicamente para o parto não se estabelecerá esta corrente negativa, e ela achará a experiência agradável e guardará uma lembrança feliz.

Parte prática:

Durante a explicação dos exercícios tanto as gestantes como o professor deverão ficar em posição de Sastre ou de Buda, (sentada no chão com as pernas cruzadas, os tornozelos apoiados e os joelhos o mais separado possível). Esta posição favorece a distensão ou elasticidade dos músculos do períneo contribuindo para a maior flexibilidade das articulações lombo-sacra e pélvica: 
SCHMIDT, M.J. \& FREDDI, W.E.S. - Preparo da gestante para o parto. Aulas teórico-práticas, Rev. Bras. Enf.; Rio de Janeiro, 28 : 15-25, 1975.

favorecendo a ampliação do canal de parto.

Exercício respiratório n. ${ }^{\circ}$ 1: respiração profunda.

Finalidade: aumentar a capacidade respiratória e melhorar a oxigenação materna e fetal.

\section{Técnica:}

1. em posição dorsal, colocar as mãos espalmadas, em forma de $\mathrm{V}$ invertido, sobre o lado das costelas, (abaixo das mamas);

2. com a boca fechada, inspirar profundamente pelo nariz até sentir as costelas contra as mãos;

3. reter o ar inspirado durante 15 ou 30 segundos, grada'tivamente, podendo atingir até 60 segundos;

4. expirar lentamente, pelo nariz forçando o final para eliminar o ar residual;

5. inspirar lentamente até o máximo da capacidade pulmonar e expirar sem forçar a saída do ar residual.

\section{Observações:}

a) a posição das mãos permitirá constatar a correta execução do exercício, pois a redução e expansão do tórax será sentida em cada movimento.

b) este exercício poderá ser feito em posição sentada.

Exercício de relaxamento muscular.

Para melhor favorecer o relaxamento muscular, seria ideal um ambiente semi-escuro, silencioso, com música suave e temperatura agradável. Entretanto, não é este o ambiente normalmente encontrado nas maternidades. Portanto, o curso deve condicionar as gestantes a relaxar em qualquer ambiente.
Finalidade:

descontrair a musculatura durante 0 trabalho de parto, favorecendo a dilatação do colo uterino e evitando a tensão emocional. Deve ser usada durante os intervalos das contrações do trabalho de parto.

Técnica:

1. em posição dorsal, apoiar bem todas as partes do corpo, evitando qualquer esforço;

2. para induzir a gestante ao relaxamento e formar um reflexo condicionado, o professor deverá sugerir a despreocupação de suas atividades diárias, falando sempre no mesmo tom de voz, e pausadamente, o seguinte:

- Vamos relaxar...

- Vamos esquecer as preocupações de casa, do trabalho, o barulho da rua, o movimento das pessoas...

- Sinto os olhos cansados..., pesados..., pesados... (contrair e relaxar os olhos, mantendo-os semi-serrados);

- Sinto a boca cansada..., pesada... (contrair e relaxar);

- Sinto o rosto cansado..., pesado..., pesado... (contrair e relaxar);

- Sinto o ombro direito cansado..., pesado..., pesado... (contrair e relaxar);

- Sinto o braço direito cansado.... pesado..., pesado... (contrair e relaxar-;

- Sinto o ombro esquerdo cansado..., pesado..., pesado... (contrair e relaxar);

- Sinto o braço esquerdo cansado..., pesado..., pesado... (contrair e relaxar);

- Sinto o tórax cansado..., pesado..., pesado... (contrair e relaxar);

- Sinto a bacia cansada..., pesada.., pesada... (contrair principal- 
SCFMIDT, M.J. \& FREDDI, W.E.S. - Preparo da gestante para o parto. Aulas teórico-práticas, Rev. Bras. Enf.; Rio de Janeiro, 28 : 15-25, 1975.

mente e musculatura perineal e relaxar);

- Sinto a perna direita cansada..., pesada..., pesada... (contrair e relaxar);

- Sinto a perna esquerda cansada..., pesada.., pesada... (contrair e relaxar);

- Sinto todo o corpo cansado..., pesado..., pesado... (soltar bem todo o corpo, como se fosse atravessar o chão) ;

- Relaxe bem todo o corpo... bem relaxado..., bem relaxado.. ;

- Está bom... vamos respirar!

Observações: a respiração de expansão pulmonar favorece o relaxamento muscular. O relaxamento deverá ser treinado também em posição de Sims e sentada.

\section{Segunda Aula}

Parte teórica - noções de anatomia e fisiologia do aparelho reprodutor feminino.

\section{Objetivo:}

mostrar como a mulher tem condiçōes físicas para exercer a função da maternidade.

Desenvolvimento do assunto.

A - Descrição dos ovários, trompas: útero e vagina.

B - Breve descrição da hipófise e de sua influência nas transformações físicas e psíquicas que ocorrem na puberdade.

C - Fisiologia e higiene da menstruação.

Parte prática:

Exercício respiratório n. ${ }^{\circ}$ 2: respiração of egante.
Finalidade: evitar que o diafragma, no seu abaixamento inspiratório, excite o útero comprimindo-o.

Técnica:

1. Em posição dorsal, fazer duas inspirações profundas, pelo nariz, expirando lentamente pela boca (dois suspiros sentidos);

2. com a boca semi-fechada, como no assovio, soprar lenta e regularmente: como se estivesse querendo dobrar a chama de uma vela, sem apagá-la;

3. manter a respiração acima descrita, acompanhando o ritmo da contração uterina, isto é, no início lenta acelerando no ápice da contração e diminuindo lentamente até que esta termine (ritmo de um trem que parte da estação lentamente, aumenta a velocidade no meio do caminho e volta a diminuir a mesma até parar na próxima estação) ;

4. terminada a contração, fazer novamente duas respirações profundas.

Observação: esse exercício respiratório deverá ser treinado durante a gestação, iniciando-se com 15 segundos aumentando gradativamente, até atingir 60 segundos, que é o tempo que poderá durar a contração uterina.

Exercício de ginástica $n .^{\circ} 1$ : rotação do pé.

Finalidade: exercitar os músculos abdominais, especialmente os retos abdominais, favorecendo a circulação dos membros inferiores, prevenindo varizes e flebites.

\section{Técnica:}

1. Em plano duro, posição dorsal completa, braços estendidos ao longo do corpo, colocar o pé direito em posição de balé;

2. levantar a perna direita aproximadamente $15 \mathrm{~cm}$ do solo, e descrever 
SCHMIDT, M.J. \& FREDDI, W.E.S. - Preparo da gestante para o parto. Aulas teórico-práticas, Rev. Bras. Enf.; Rio de Janeiro, 28 : 15-25, 1975.

no ar três círculos de cerca de $20 \mathrm{~cm}$ de diâmetro;

3. abaixar a perna direita e fazer o mesmo com a perna esquerda;

4. com os pés na posição de balé, juntar os calcanhares e repetir o exercicio com as duas pernas ao mesmo tempo.

Observação: recapitular o exercício respiratório $n^{\circ} 1$ e o de relaxamento muscular.

\section{Terceira aula}

Parte teórica - fecundação e desenvolvimento fetal.

Objetivos: mostrar como o bebê é concebido e cresce dentro do útero materno durante os nove meses que precedem o nascimento e discutir as mudanças que se processam no organismo materno e sua importância na higiene da gravidez.

Desenvolvimento do assunto:

A - Breve descrição dos órgãos repraduitores masculinos e da fecundação.

B - Noções do desenvolvimento fetal.

C - Breve descrição das modificações que ocorrem no organismo materno:

- aparelho respiratório $\left\{\begin{array}{l}\text { pressão do diafragma, } \\ \text { absorção do oxigênio pelo feto }(16 \%) \text {; }\end{array}\right.$

- aparelho circulatório $\left\{\begin{array}{l}\text { trabalho cardíaco adicional, } \\ \text { modificações sanguíneas (anemia gravídica); }\end{array}\right.$

- aparelho digestivo

$\{$ deslocamento dos órgãos por compressão do - aparelho digestivo

$\left\{\begin{array}{l}\text { útero, diminuição do tônus por ação da } \\ \text { relaxina, alteração das gengivas; }\end{array}\right.$

- aparelho urinário

compressão da bexiga pelo útero;

- aparelho locomotor $\left\{\begin{array}{l}\text { deslocamento do centro de gravidade, e } \\ \text { edema de articulações (queda fácil); }\end{array}\right.$

- aparelho tegumentar $\{$ manchas gravídicas (rosto, mamas, abdomen);

- aparelho reprodutor $\{$ ovários, útero, vagina e mamas. 
SCHMIDT, M.J. \& FREDDI, W.E.S. - Preparo da gestante para o parto. Aulas teórico-práticas, Rev. Bras. Enf.; Rio de Janeiro, $28:$ 15-25, 1975.

D - Discutir as alterações gravídicas e relacioná-las com os cuidados durante a gestação.

Técnica:

1. em posição dorsal, com os braços esticados lateralmente, mãos espalmadas, elevar ao máximo a perna direita, dobrando-a em seguida;

2. procurar colocar o joelho no chão, do lado oposto, sem movimentar as costas, deixando a bacia acompanhar o movimento e a cintura fazer um exercício de torsão;

3. voltar à posição anterior e repetir o exercício com a perna esquerda.

Observação: recapitular os exercícios n. ${ }^{\circ}$ s 1 e 2 de respiração, o relaxamento muscular e o exercício de ginástica n. ${ }^{\circ} 1$.

\section{Quarta Aula}

Parte teórica - trabalho de parto.

Objetivo: mostrar como o bebê nasce e ensinar a técnica de como dar a luz.

Desenvolvimento do assunto:

A - Breve descrição dos tipos de parto (normal, cesárea e forceps).

B - Sinais e sintomas do trabalho de parto:

- quando ir à maternidade;

- o que levar para a maternidade;

- o que acontece na maternidade (exame na admissão e controles);

- o que a parturiente deve fazer (como usar os exercícios treinados durante a gestação).

C - Período de dilatação:

- fisiologia da dilatação (tipo, frequência, duração e ação das contrações uterinas);

- como usar a respiração ofegante durante as contrações;
- como usar o relaxamento muscular nos intervalos das contrações.

Parte prática:

Exercício de ginástica n.o 3: flexão da coluna.

Finalidade: favorecer a flexibilidade da coluna.

Técnica:

1. Em pé, com os braços ao longo do corpo, inclinar os ombros para trás;

2. voltar à posição anterior, relaxando a musculatura do tórax e dos braços;

3. dobrar o corpo para frente, lentamente, deixando cair os braços e a cabeça, até as mãos atingirem o solo;

4. levantar vagarosamente e inclinar o corpo, colocando os ombros novamente para trás.

Observação: o importante é dobrar a coluna relaxadamente. Portanto, não é essencial não dobrar os joelhos. Recapitular os exercícios $n .{ }^{\circ} \mathrm{s} 1$ e 2 da respiração, o relaxamento muscular e os exercícios de ginástica $n .^{\circ}$ s 1 e 2 .

\section{Quinta Aula}

Parte teórica - trabalho de parto (continuação).

\section{Desenvolvimento do assunto:}

A - Período de expulsão (se possível: fazer a demonstração no manequim).

B - Fase de transição (cuidados).

C - Fisiologia da expulsão do bebê.

D - Descrever uma sala de parto (posição na mesa de parto).

E - Ensinar a técnica do período expulsivo (quando e como usar os exercícios de respiração, do expulsivo e o remador). 
SCHMIDT, M.J. \& FREDDI, W.E.S. - Preparo da gestante para o parto. Aulas teórico-práticas, Rev. Bras. Enf.; Rio de Janeiro, 28: 15-25, 1975.

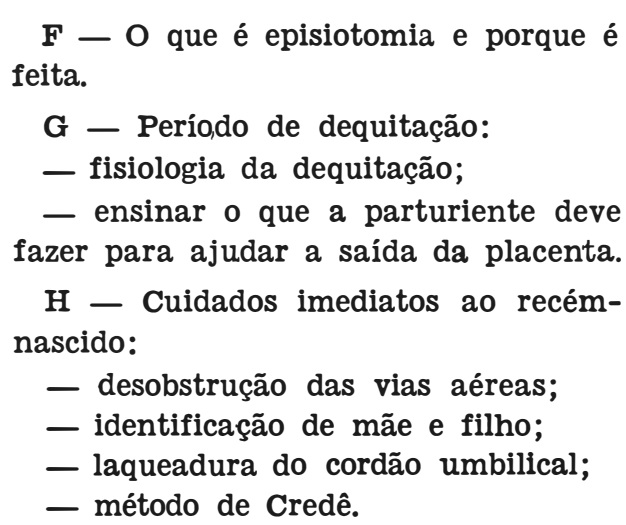

\section{Parte prática:}

Exercício de ginástica n. 4: flexão dos joelhos.

Finalidade: favorecer a flexibilidade dos músculos perineais.

Técnica:

1. Apoiar-se na ponta dos pés e colocar-se em posição de cócoras com as mãos sobre os joelhos;

2. afastar os joelhos o mais possível, forçando-os e aproximando-os novamente, repetindo o movimento três vezes;

3. levantar-se, apoiando os pés ao solo.

Observação: recapitular os exercícios n. ${ }^{\circ} \mathrm{s} 1$ e 2 de respiração, o relaxamento muscular e os exercícios de ginástica n. ${ }^{\circ}$ s 1,2 e 3 .

\section{Sexta Aula}

Parte teórica - o cuidado do bebê. Objetivo: discutir como é um recémnascido, quais são suas necessidades e como pode a mãe satisfazê-las.

Desenvolvimento do assunto:

A - Como é um recém-nascido:

- medidas e peso;
- aparência física;

- órgãos dos sentidos.

B - Comportamento do bebê.

- sono, choro e sucção.

C - Satisfação das necessidades básicas do bebê:

- alimentação;

- sono e repouso;

- eliminação;

- higiene;

- ar fresco e sol;

- proteção e amor (aceitá-lo como indivíduo);

- controle médico periódico.

Observação: nesta aula, poderá ser distribuída uma relação de enxoval do bebê, incluindo roupas e equipamentos.

Parte prática:

Exercício de ginástica n. ${ }^{\circ}$ 5: balanceio da pelve.

Finalidade: favorecer a flexibilidade dos músculos, preparando para o exerlício do remador.

\section{Técnica:}

1. Colocar-se em posição de "gatinhas", apoiando-se nos joelhos afastados e nas mãos, com os dedos voltados para dentro;

2. levantar lentamente a cabeça e tornar as costas côncavas, descontraindo os músculos do glúteo e do períneo;

3. contrair esses músculos e os abdominais, inclinar a cabeça, procurando colocar o mento no externo e arredondar as costas;

4. descontrair, levantar a cabeça, e dobrar as articulações dos cotovelos, fazendo três vezes o movimento de cima para baixo.

Observação: recapitular os exercícios n. ${ }^{\circ}$ s 1 e 2 de respiração, o relaxamento 
SCHMIDT, M.J. \& FREDDI, W.E.S. - Preparo da gestante para o parto. Aulas teórico-práticas, Rev. Bras. Enf.; Rio de Janeiro, 28 : 15-25, 1975.

muscular e os exercícios de ginástica n. ${ }^{\circ}$ s $1,2,3$ e 4 .

\section{Sétima Aula}

Parte teórica - alimentação e banho do bebê.

Objetivo: mostrar à mãe um modo simples de cuidar da alimentação e de banhar o bebê e ajudá-la a sentir-se segura nestas atividades.

Desenvolvimento do assunto:

A - Alimentação nos primeiros dias:

- cuidados com os utensílios;

- hidratação (água simples ou preparada, chá etc.);

- amamentação natural (vantagens

e técnica de amamentação);

- amamentação artificial (preparo da mamadeira);

B - Higiene do recém-nascido:

- tipos de banho;

- troca de fraldas;

- banho de bacia (se possível fazer uma demonstração);

- quando dar o 1. ${ }^{\circ}$ banho (local e horários) ;

- material.

C - Cuidado com o umbigo:

- curativo umbilical;

- queda do coto umbilical.

Parte prática:

Exercício de respiração n. 3: respiração de período expulsivo.

Exercício de ginástica n. ${ }^{\circ}$ 6: exercício do remador.

Finalidade: formar a prensa abdominal para ajudar a expulsão do bebê.

Técnica:

1. Respirar profundamente uma ou duas vezes;
2. inspirar e conter a respiração;

3. levantar a cabeça, colocando o mento no externo, e contrair energicamente os músculos abdominais, relaxando os perineais;

4. conter a respiração durante a contração de expulsão (bloqueio respiratório).

Exercício do remador:

Finalidade: favorecer o período expulsivo do parto.

Técnica:

1. Em posição dorsal completa, flexionar as pernas e afastar os joelhos;

2. Com os braços em posição de remador, colocar as mãos abaixo das articulações dos joelhos e dobrar as pernas sobre o abdomem;

3. fazer três vezes o movimento de balanceio, para frente e para trás.

Observação: este exercício deverá ser feito juntamente com a respiração do período expulsivo.

Oitava Aula

Parte teórica - puerpério.

Objetivo: informar a respeito das mudanças que ocorrem durante o puerpério e o cuidado que as mães precisam ter neste período.

Desenvolvimento do assunto:

A - Breve descrição das modificações após o parto:

- puerpério imediato e mediato.

B - Cuidados higiênicos no hospital e em casa:

- higiene corporal banho e lavagem externa;

- cuidados com os seios; 
SCHMIDT, M.J. \& FREDDI, W.E.S. - Preparo da gestante para o parto. Aulas teórico-práticas, Rev. Bras. Enf.; Rio de Janeiro, 28 : 15-25, 1975.

- perdas genitais;

- alimentação;

- repouso e exercícios (ginásticas);

- exame pós-natal.

\section{Parte prática:}

Demonstração dos exercícios de pósparto.

Finalidade: favorecer a recuperação da musculatura abdominal, fazendo-a voltar ao funcionamento anterior à gravidez.

Desde o primeiro dia pós-parto, a puerpera poderá usar a posição de decúbito ventral, para facilitar a correta posição do útero.

A partir do segundo dia pós-parto, poderá iniciar os seguintes exercícios:

Exercício de ginástica $n .^{\circ} 7$ : flexão de cabeça.

Técnica:

1. Em posição dorsal, sem travesseiros, procurar encostar o mento no externo sem movimentar outras partes do corpo;

2. repetir o movimento três vezes.

A partir do terceiro dia pós-parto, poderá iniciar o exercício de ginástica $n .^{\circ}$ 1 , rotação de pé.

A partir do $15 .^{\circ}$ dia pós-parto, poderá iniciar $o$ exercício de ginástica $n .^{\circ} 2$, rotação da pelve.

Após o término da amamentação natural, poderá iniciar os exercícios para fortalecer a musculatura do busto.

Exercício de ginástica $n .^{\circ}$ 8: arco dos braços.

\section{Técnica:}

1. Em pé, colocar o braço direito, por trás e acima da cabeça, procurando tocar o ombro esquerdo, com a ponta dos dedos;
2. ao mesmo tempo colocar a māo esquerda na cintura do lado direito;

3. repetir o exercício dez vezes, alternando os braços.

\section{CONCLUSÃO}

O preparo psico-físico para o parto deve fazer parte integrante da assistência pré-natal, como ajuda inestimável na correção das causas que pertubam ou determinam o desequilíbrio físico, psíquico ou social da gestante; além disso, a gestante preparada estará em melhores condições de cooperar durante $o$ trabalho de parto e o parto, bem como de cuidar-se no puerpério, e de dar uma assistência conveniente ao filho.

Este preparo não lhe garante um parto normal, pois sabemos que, eventualmente, poderá haver intercorrências obstétricas que indicarão uma cirurgia; porém, nesta eventualidade, a parturiente estará preparada para o período de dilatação (o mais longo do trabalho de parto) e apresentará melhores condições operatórias.

Parece-nos, pois, de grande importância que as enfermeiras incentivem a realização desse curso, preparando a gestante física e psiquicamente para o parto. Embora as nossas maternidades não apresentem condições ideais para a sua aplicação, estas gestantes, quando bem preparadas, serão divulgadoras do método para a equipe hospitalar, que o desconhece, mostrando-lhe, praticamente, os benefícios indiscutíveis do preparo psico-físico para o parto. Isto, evidentemente, provocará uma modificação na relação entre o pessoal técnico e a parturiente, o que contribuirá para transformar substancialmente o clima nas salas de pré-parto e de parto, resultando em uma melhor assistência à parturiente e ao recém-nascido. 